\section{Electrical Charge of the Antigen Determines Intraarticular Antigen Handling and Chronicity of Arthritis in Mice}

Wim B. van den Berg, Levinus B. A. van de Putte, Wil A. Zwarts, and Leo A. B. Joosten

Department of Rheumatology, University Hospital, Nijmegen, The Netherlands
A joint and on the ability of the antigen to induce chronic arthritis. Three different antigens were used: anionic native bovine serum albumin (BSA), and charge modified BSA made cationic (pI 8.5) either by methylation (mBSA), or amidation (aBSA). ${ }^{125}$ I-labeled antigen was injected into the knee joints of nonimmune mice and of mice immunized with antigen in Freund's complete adjuvant. Intraarticular antigen retention of the cationic antigens mBSA and aBSA was significantly increased compared with native BSA, both in immune and nonimmune mice. In vitro studies indicated the electrostatic character of the binding of the cationic antigens to joint tissues and confirmed the large difference in antigen retention of the antigens found in vivo. A 100-fold amount of cationic antigen could be bound to noncartilaginous collagenous tissue of the joint compared with antibody-mediated trapping of native BSA, and for hyaline articular cartilage, this difference was even greater. In immunized mice, chronic arthritis only developed after intraarticular injection of the cationic antigens. This phenomenon was apparently related to increased retention of $\mathrm{mBSA}$ and aBSA compared with BSA, since delayed hypersensitivity and humoral immunity were comparable for the three antigens used. Our data indicate that antigenic charge is an important determinant of antigen handling by the joint and, in addition, support the concept that the development of

Address correspondence to Dr. van den Berg.

Received for publication 21 November 1983 and in revised form 12 July 1984.

J. Clin. Invest.

(C) The American Society for Clinical Investigation, Inc.

$0021-9738 / 84 / 11 / 1850 / 10 \quad \$ 1.00$

Volume 74, November 1984, 1850-1859 chronic arthritis depends on the amount of antigen retained in the joint.

\section{Introduction}

Antigen trapped by immune complex formation within the collagenous tissues of the joint may provide the stimulus responsible for the chronicity of some forms of chronic arthritis. Immune complex deposits have been found in the cartilage of animals with antigen-induced arthritis, both in the rabbit (1, 2 ) and recently in the mouse (3), and these antigen containing deposits may play a role in the chronicity of the inflammation by slowly releasing sequestered antigen from the cartilage into the synovial cavity. In addition, immunofluorescence and electronmicroscopic studies have demonstrated Ig- and complement-containing deposits in rheumatoid articular cartilage $(4,5)$. Studies on the mechanism of antigen trapping showed that antigen retention occurs by in situ immune complex formation rather than by deposition of preformed complexes (6-8).

Recently, attention has been focused on charge as an important determinant in local antigen retention. Anionic sites in the glomerular basement membrane have been shown to have affinity for cationic agents and such molecules may serve as planted antigen for circulating antibody, thereby generating more antigen retention. The nephritogenic potential of such agents was substantiated by establishing severe experimental immune complex nephritis with cationized antigens $(9,10)$. The negative fixed charge density of cartilage suggests the possibility that similar phenomena can occur in the joint.

In the present study, we investigated the influence of charge of the antigen on intraarticular antigen handling in nonimmune and immune mice using three different antigens: negatively charged native bovine serum albumin (BSA), the antigen commonly used for arthritis induction in rabbits $(2,11)$; methylated BSA (mBSA) ${ }^{1}$, the cationic antigen used to induce

1. Abbreviations used in this paper: aBSA, amidated bovine serum albumin; aOA, amidated ovalbumin; FCA, Freund's complete adjuvant; FIA, Freund's incomplete adjuvant; mBSA, methylated BSA; R/L ratio, right/left ratio; ${ }^{99 \mathrm{~m}} \mathrm{Tc},{ }^{99 \mathrm{~m}} \mathrm{Technetium}$ pertechnetate. 
murine arthritis (12); and amidated BSA (aBSA), the cationic antigen used in experimental nephritis (9). The results indicate that intraarticular retention of cationic mBSA and aBSA is significantly increased compared with anionic BSA. In immune mice, chronic arthritis developed in mBSA- and aBSA-induced, but not in BSA-induced joint inflammation. Data are presented indicating that this difference is related to increased chargemediated intraarticular antigen retention rather than differences in cellular and humoral immunity.

\section{Methods}

Animals. Male C57Bl mice aged 6-8 wk at the start of the immunization were used. Animals injected with ${ }^{125} \mathrm{I}$-antigens were given water containing $\mathrm{KI}(50 \mathrm{mg} / \mathrm{liter}) 2 \mathrm{~d}$ before injection and maintained on this water thereafter.

Antigens. BSA and mBSA were obtained from Sigma Chemical Co., St. Louis, MO. BSA was used unmodified as native BSA and used as a substrate to prepare aBSA, according to the method of Danon et al. (13), using 1-ethyl-3(3 dimethyl-aminopropyl)carbodiimide hydrochloride (EDC; Sigma Chemical Co.) as activator and $N, N$-dimethyl1,3-propanediamine (DMPA; BDH Chemicals Ltd., Poole, England) as a nucleophile. In brief, $0.5 \mathrm{ml}$ DMPA was added to $25 \mathrm{ml}$ distilled water with continuous stirring and the $\mathrm{pH}$ was adjusted to 6.5 with 1 $\mathrm{N} \mathrm{HCl}$. Then, $20 \mathrm{ml}$ of an aqueous solution of protein $(50 \mathrm{mg} / \mathrm{ml})$ and $600 \mathrm{mg}$ EDC were added. The mixture was left at room temperature for $6 \mathrm{~h}$ under $\mathrm{pH}$ adjustment $(\mathrm{pH}=6.5$ ) with $1 \mathrm{~N} \mathrm{HCl}$, followed by exhaustive dialysis against distilled water and lyophilization.

Iodination of antigens. ${ }^{125}$-labeling was performed by the chloramine $T$ method (14). ${ }^{125}$ I-antigen was separated from free ${ }^{125}$ I by Sephadex G25 fractionation. The specific activity was $\sim 3 \mu \mathrm{Ci} / \mu \mathrm{g}$.

Determination of isoelectric point. The isoelectric point of the various proteins was determined in a slab gel of $5 \%$ polyacrylamide and an ampholyte $\mathrm{pH}$ gradient ranging from 3.5 to 9 .

Immunization. Mice were immunized according to the immunization protocol scheduled in Table I. In brief, animals received $0.1 \mathrm{ml}$ antigen in Freund's complete or incomplete adjuvant emulsion (Difco
Laboratories, Detroit, MI) by divided injections into the flank skin and the footpads of the forelegs. On both occasions, $2.10^{9}$ heat-killed Bordetella Pertussis organisms (National Institute of Public Health, Bilthoven, The Netherlands) were administered intraperitoneally as an additional adjuvant. Booster injections were given in the forelegs.

Skin testing. Delayed hypersensitivity was measured at $48 \mathrm{~h}$ after injection of $5 \mu \mathrm{g}$ antigen in $10 \mu \mathrm{l}$ saline into the pinna of the ear. In the highly boostered mice, enough BSA was retained at the ear test site by antibody-mediated trapping to permit the manifestation of a delayed reaction (15). Increase in ear thickness was measured with an engineers micrometer.

Antibody determination. Antibodies were measured with an ELISA assay. Antigen was coated on microtiter plates (Greiner, Alphen a/d Rijn, the Netherlands) in a concentration of $100 \mu \mathrm{g} / \mathrm{ml}$. Antibody titers were assessed by twofold serial dilution of the sera followed by detection of bound mouse Ig with 1:500 diluted peroxidase-conjugated rabbit anti-Mouse Ig (Miles Laboratories, Inc., Elkhart, IN). $O$-phenylenediamine $(1 \mathrm{mg} / \mathrm{ml})$ was used as substrate for peroxidase and the antibody titer was determined by using 50\% of the maximal extinction as an endpoint. Ouchterlony assays were performed with a fixed BSA concentration $(0.1 \mathrm{mg} / \mathrm{ml})$ and two $\log$ dilutions of the antiserum. The Ouchterlony titer was expressed as the highest serum dilution (2 log value) giving a visible precipitation line. As a positive control, highly boostered rabbit anti-BSA serum, used in the in vitro antigen binding experiments (see below), was taken which has an Ouchterlony titer of 6 .

Experimental design. Antigen elimination and retention was studied in the knee joint with three different antigens in both immune and nonimmune mice (Table I). The studies in nonimmune mice were performed to obtain data on the charge-mediated nonimmune binding of the negatively-charged (native BSA) and positively-charged (mBSA and aBSA) proteins. The studies in mice immunized with antigen in Freund's complete adjuvant (FCA) were performed to obtain information on antibody-mediated retention and on a possible relation between antigen retention in the knee joint and the development of chronic joint inflammation. Immunization with antigen in FCA induces both antibodies and delayed hypersensitivity, which is a prerequisite for the development of chronic arthritis in the rabbit (16). In addition,

Table I. Immune Status After Various Immunization Protocols

\begin{tabular}{|c|c|c|c|c|c|c|c|c|}
\hline \multirow[b]{2}{*}{ Group } & \multirow[b]{2}{*}{ Time* } & \multirow[b]{2}{*}{ Immunization $\ddagger$} & \multirow[b]{2}{*}{ Booster } & \multicolumn{2}{|c|}{ Antibody titer } & \multicolumn{3}{|c|}{ Ear test } \\
\hline & & & & ELISA§ & Ouchterlony" & BSA & mBSA & aBSA \\
\hline & $w k$ & & & & & & & \\
\hline 1 & - & 一 & - & 0 & 0 & 0 & $1 \pm 1$ & $1 \pm 1$ \\
\hline 2 & 3 & $0.1 \mathrm{mg} \mathrm{BSA} / \mathrm{FCA}$ & - & $11 \pm 1$ & 0 & ND & ND & ND \\
\hline 3 & 6 & $0.1 \mathrm{mg} \mathrm{BSA} / \mathrm{FCA}$ & $0.5 \mathrm{mg} \mathrm{BSA} / \mathrm{FCA}$ & $14 \pm 1$ & $4 \pm 1$ & $30 \pm 3$ & $5 \pm 2$ & ND \\
\hline 4 & 3 & $0.5 \mathrm{mg} \mathrm{BSA} / \mathrm{FIA}$ & - & $13 \pm 1$ & $2 \pm 1$ & ND & ND & ND \\
\hline 5 & 6 & 0.5 mg BSA/FIA & $0.5 \mathrm{mg} \mathrm{BSA} / \mathrm{FIA}$ & $14 \pm 1$ & $3 \pm 1$ & $14 \pm 5$ & $3 \pm 1$ & ND \\
\hline 6 & 3 & $0.1 \mathrm{mg} \mathrm{mBSA} / \mathrm{FCA}$ & - & $8 \pm 2$ & ND & $9 \pm 1$ & $35 \pm 3$ & $13 \pm 4$ \\
\hline 7 & 3 & $0.1 \mathrm{mg} \mathrm{aBSA} / \mathrm{FCA}$ & - & $10 \pm 1$ & ND & ND & ND & $22 \pm 5$ \\
\hline
\end{tabular}

ND, not determined. Values are the mean of the determinations in (sera of) at least five mice. * Weeks after first immunizing injection. ¥ Immunizing injections were given on days 0 and 7 and boosters after 4 wk. $\$$ Mean $\pm S D$, expressed as $2 \log$ values, using 50\% of the maximal extinction as end-point. "The highest serum dilution, expressed as $2 \mathrm{log}$ value, giving a visible line against $0.1 \mathrm{mg}$ antigen/ml. I Mean values $\pm \mathrm{SD}$ of increase in ear thickness $\left(\mathrm{mm} \times 10^{-2}\right)$ measured $48 \mathrm{~h}$ after the injection of $5 \mu \mathrm{g}$ antigen in $10 \mu \mathrm{l}$ saline. 
antibody-mediated retention of native BSA was studied in mice immunized with antigen in Freund's incomplete adjuvant (FIA) (group 5, Table I).

Antigen retention measurements. ${ }^{125} \mathrm{I}$-labeled antigen $(6 \mu \mathrm{l})$ was injected into the right knee joint, whereas the left knee joint received $6 \mu \mathrm{l}$ saline. At various days thereafter (see Results), ${ }^{125} \mathrm{I}$-radioactivity of both knee joints was measured by external $\gamma$-counting as described for ${ }^{99 \mathrm{~m}} \mathrm{Tc}$ uptake measurements (see below). Values of the right knee were corrected for that of the left knee, which represent background activity. In one experiment, knee joints and the spleen were dissected and retained activity was counted in a scintillation counter of the well type. Antigen retention in the knee joint was expressed in absolute terms or as percentage of the initial count rate measured immediately after antigen injection.

${ }^{99 m} T c$ uptake measurements. Joint inflammation was determined by ${ }^{99 \mathrm{~m}} \mathrm{Tc}$ pertechnetate uptake measurements of the knee joints. This method makes use of the increased accumulation of a systemically administered small isotope at the inflamed site, which is due to augmented blood flow and tissue swelling. The method has been described in detail elsewhere (17), and ${ }^{99 \mathrm{~m}} \mathrm{Tc}$ uptake values correlate well with histological parameters of joint inflammation (18). In brief, $10 \mu \mathrm{Ci}{ }^{99 m} \mathrm{Tc}$ was injected subcutaneously in the neck region, and 30 min later, the $\gamma$-radiation over the knee joints was measured with a Thallium-activated $\mathrm{NaI}$ scintillation crystal with careful shielding of the radioactivity in the rest of the body (17). The animals were sedated $10 \mathrm{~min}$ before the measurement by intraperitoneal administration of $0.1 \mathrm{ml} 4.5 \%$ chloralhydrate $/ 10 \mathrm{~g}$ body weight. Arthritis was scored as the ratio of the ${ }^{99 m} \mathrm{Tc}$ uptake in the right vs. that in the left knee joint $(\mathrm{R} / \mathrm{L}$ ratio). $\mathrm{R} / \mathrm{L}$ ratios exceeding 1.1 were taken to indicate inflammation of the right knee (17). Values $>1.1$ were never found after intraarticular injection of native or cationic antigens in nonimmune mice. When Tc uptake measurements were performed in animals containing ${ }^{125} \mathrm{I}$-labeled antigen in the joint, Tc uptake values were corrected for ${ }^{125}$ I-counts.

Effect of inflammation on antigen retention. To investigate the effect of inflammation on antigen clearance, mice were immunized with amidated ovalbumin (aOA) in FCA as described for aBSA. $3 \mathrm{wk}$ later, one knee joint was injected with $60 \mu \mathrm{g}{ }^{125} \mathrm{I}-\mathrm{aBSA}$ in $6 \mu \mathrm{l}$ saline and the contralateral knee was injected with both ${ }^{125} \mathrm{I}-\mathrm{aBSA}$ and either 6 or $0.6 \mu \mathrm{g} \mathrm{aOA}$. The retention of ${ }^{125} \mathrm{I}-\mathrm{aBSA}$ was measured by external gamma counting as described and the joint inflammation induced by aOA was measured with ${ }^{99 \mathrm{~m}} \mathrm{Tc}$ uptake. In a control experiment, the competitive effect of concomitant intraarticular injection of aOA on ${ }^{125} \mathrm{I}$-aBSA retention was investigated in nonimmunized mice. No inflammation developed and no effect of aOA on ${ }^{125} \mathrm{I}-\mathrm{aBSA}$ retention was found. In an additional group of nonimmune mice, joint inflammation was induced with zymosan. One joint was injected with $60 \mu \mathrm{g}$ ${ }^{125} \mathrm{I}-\mathrm{aBSA}(6 \mu \mathrm{l})$ and either 180 or $18 \mu \mathrm{g}$ zymosan, and the contralateral joint was injected with ${ }^{125} \mathrm{I}$-aBSA alone. The zymosan particles were precoated with aBSA by preincubation in a solution of $30 \mathrm{mg}$ aBSA $/ \mathrm{ml}$ for $30 \mathrm{~min}$ at $37^{\circ} \mathrm{C}$ to prevent interference of zymosan with the intraarticular antigen handling by binding of ${ }^{125} \mathrm{I}-\mathrm{aBSA}$ to the concomitantly injected zymosan particles.

In vitro studies. Patellae with surrounding tissue were removed from the knee joint of normal mice by cutting the patellar ligament, followed by careful dissection of the patella leaving it embedded in surrounding tissue to prevent damage to the patellar cartilage. Tissue specimens were placed in microtiter plates containing $100 \mu \mathrm{l}$ phosphatebuffered saline (PBS). Tissues were either preincubated in $100 \mu \mathrm{l}$ normal rabbit serum or high-titered rabbit anti-BSA serum (Ouchterlony titer, 1:64), or directly incubated in PBS containing ${ }^{125}$ I-antigen. Due to the large amounts of antibodies needed, we used a rabbit anti-BSA serum, but similar antigen trapping can be obtained with mouse antiBSA serum from highly boosted mice. All incubations were performed for $2 \mathrm{~h}$ at $37^{\circ} \mathrm{C}$. Antigen concentration was $0.3 \mathrm{mg} / \mathrm{ml}$, unless stated otherwise, and the specific activity ranged from 2,000 to $20,000 \mathrm{cpm} /$ $\mu \mathrm{g}$, enabling detection of antigen binding at the nanogram level. After termination of the incubation, the tissues were exhaustively washed by three changes in $10 \mathrm{ml}$ PBS under continuous shaking to remove unbound radioactivity. To discriminate between antigen bound at the surrounding collagenous tissue and the hyaline cartilage of the patella, the tissue specimens were fixed in 10\% formalin and decalcified in $5 \%$ formic acid. After this procedure, the whole patella with its cartilage intact could easily be dissected from the surrounding collagenous tissue. This method, named the patella assay, has been described in detail elsewhere and is now routinely used for the measurement of chondrocyte function in intact articular cartilage (19). The amount of antigen bound at the surrounding collagenous tissue is expressed per $5 \mathrm{mg}$ wet tissue, which is the approximate weight of the whole structure. This represents a rather inhomogeneous structure, but Teuscher et al. (7) described that in situ immune complex formation was not very different in various connective tissues and our data are in accordance with this. Cartilage binding is expressed as micrograms of antigen bound per cartilage of the whole patella, which is a defined anatomical entity. Only the surface of the patella consists of cartilage $(10-50 \mu \mathrm{g})$ and autoradiographic studies revealed that antigen retention was restricted to this layer and does not extend to the underlying bony structures. The rabbit anti-BSA serum used in the in situ immune complex formation experiments gave antibody-mediated binding of native BSA in a range of two to four times higher than that obtained with mouse anti-BSA sera from highly boostered mice (groups 3 and 5, Table I). Autoradiographic controls performed on histological sections revealed that antigen binding of the patella was restricted to the cartilage, with the absence of label in bone marrow and bone, indicating that binding at the whole patella can be used as a measure of cartilage binding. To investigate the effect of $\mathrm{pH}$ and ionic strength on antigen binding, incubations were performed in glycine- $\mathrm{NaCl}$ buffers of varying pH and molarity. To investigate the effect of proteoglycan depletion of the cartilage on subsequent antigen binding, tissue specimens were pretreated with trypsin $(0.7 \mathrm{mg} / \mathrm{ml})$ for $1 \mathrm{~h}$ at $37^{\circ} \mathrm{C}$. To make sure that this treatment causes proteoglycan depletion, the cartilage was prelabeled by incubation with ${ }^{35} \mathrm{~S}$-sulphate $(10 \mu \mathrm{Ci} / \mathrm{ml}$ for $2 \mathrm{~h})$, and proteoglycan loss was registered as decrease in ${ }^{35} \mathrm{~S}$-content of the cartilage.

\section{Results}

Fig. 1 shows the pI of native BSA and the charge-modified cationic antigens, mBSA and aBSA. The pI of both cationic antigens was almost identical (pI, 8.5).

Retention of native BSA. To investigate antigen elimination and retention, ${ }^{125}$ I-labeled $\mathrm{BSA}$ was injected into the right knee joint of both immune and nonimmune mice. Whether immune elimination or just immune retention occurred in the knee joint depended entirely upon the immune status of the immunized mice. Using the immunization protocol for mBSAinduced arthritis, the animals developed high antibody titers (Table I, group 2), but after intraarticular injection of $60 \mu \mathrm{g}$ 


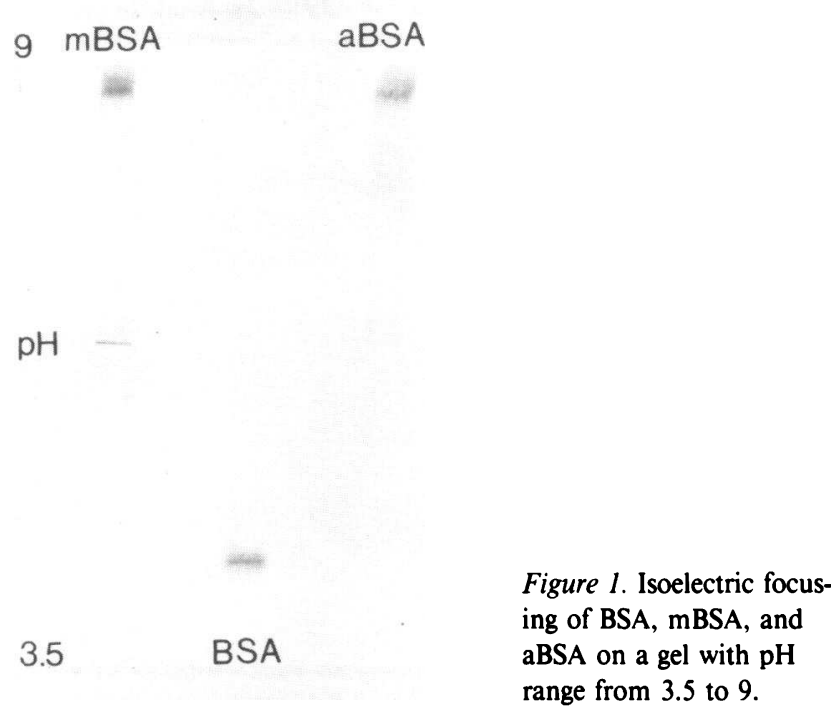

BSA, immune retention in the knee joint could not be demonstrated. Comparison with nonimmune mice revealed the well-established immune elimination phenomenon in the blood, but the antibody titer is apparently not high enough to obtain substantial antigen retention in the knee joint (Table II). To further increase the antibody titer, these mice were once more boosted with a high dose of antigen (Table I, group 3). As shown in Fig $2 a$, in this case, immune retention was found in the joint of these animals, but the amount of antigen retained is still low.

Retention of cationic BSAs. In contrast to the minimal retention of native BSA, high amounts of the cationic antigens

Table II. Amount of ${ }^{125}$ I in Different Compartments at Various Days after Intraarticular Injection of $60 \mu{ }^{125} I-B S A$ into the Right Knee Joint

\begin{tabular}{ccccccc}
\hline & Days & $\begin{array}{l}\text { Right } \\
\text { knee* }\end{array}$ & $\begin{array}{l}\text { Left } \\
\text { knee }\end{array}$ & $\Delta(\mathrm{R}-\mathrm{L})$ & Spleen & Blood $\neq$ \\
\hline Nonimmune & 2 & $0.077 \S$ & 0.044 & 0.033 & 0.034 & 2.54 \\
mice: & 4 & 0.032 & 0.011 & 0.021 & 0.007 & 0.66 \\
& 7 & 0.016 & 0.002 & 0.014 & 0.002 & 0.13 \\
& 28 & 0.006 & 0.001 & 0.005 & 0.000 & $\mathrm{ND}$ \\
Immune & 2 & 0.029 & 0.002 & 0.027 & 0.019 & 0.051 \\
mice": & 4 & 0.016 & 0.001 & 0.015 & 0.014 & 0.023 \\
& 7 & 0.012 & 0.001 & 0.011 & 0.007 & 0.003 \\
& 28 & 0.004 & 0.000 & 0.004 & 0.002 & $\mathrm{ND}$ \\
& & & & & & \\
\hline
\end{tabular}

Values are expressed as percentage of the intraarticular injected dose.

* Radioactivity measurements of dissected whole knee joints.

¥ Radioactivity in $1 \mathrm{ml}$ blood.

$\S$ Mean values of at least three mice.

"Mice were immunized as indicated in Table I, group 2.
mBSA and aBSA are retained in the joint (Fig. $2 b$ and $c$ ). Even more cationic antigen is retained in the knee joint of nonimmune mice as compared with the retention of cationic antigen in immunized mice, indicating that retention of high amounts of these antigens can occur by nonimmune binding.

Localization. Autoradiography on whole joint sections of immune mice revealed that BSA was retained predominantly in fibrous cartilage and ligaments, whereas mBSA (3) and aBSA were retained also at hyaline cartilage, the most striking observation being the deep penetration of aBSA in this structure (manuscript in preparation).

Arthritis induction. The severity of joint inflammation induced with the three antigens is shown in Table III. R/L ratios of ${ }^{99 \mathrm{~m}} \mathrm{Tc}$ uptake of the right and left knee joint $>1.1$ were taken to indicate joint inflammation (17). In contrast to the clear induction of long lasting joint inflammation with the cationic antigens, $\mathrm{R} / \mathrm{L}$ ratios $>1.1$ were not found for native BSA. Histologic examination on whole joint sections confirmed the presence of inflammation in the former ones and the absence of clear joint inflammation in the latter case. This seems to be related to insufficient antigen retention rather than inadequate delayed hypersensitivity, since delayed ear swelling could be demonstrated in these animals (Table I). The importance of sufficient antigen retention for the induction of arthritis is once more stressed by the observation that injection of lower doses of the cationic antigens resulted in significantly less inflammation (Table III).

Dose-dependency of antigen retention. Since joint inflammation may influence antigen clearance and retention (20), we first examined the phenomenon of dose-dependent antigen retention under noninflammatory conditions, i.e., in animals immunized with antigen in FIA for the antibody-mediated trapping of native BSA, and in nonimmune mice for chargemediated nonimmune binding of the cationic antigens. The amount of BSA retained was not very different whether a high or a low dose of the antigen was injected (Fig. $3 \mathrm{Aa}$ ). The antibody-mediated trapping of native BSA will depend on the antibody concentration, and although the antibody titer is high in these mice (Table I, group 5), the capacity to retain antigen in the joint is low $(<0.1 \mu \mathrm{g})$. Both for mBSA and aBSA, the amount of antigen retained is much higher after injection of $60 \mu \mathrm{g}$ as compared with $6 \mu \mathrm{g}$ (Fig. $3 A b, A c$ ). This indicates that much higher amounts of antigen could be retained by charge-mediated nonimmune binding as compared with antibody-mediated trapping. Fig. $3 B$ shows the dose-dependent retention pattern in mice immunized with antigen in FCA. Comparison of Fig. $3 \mathrm{Aa}$ and Fig. $3 \mathrm{Ba}$ revealed no major difference in the retention pattern of native BSA in groups 5 and 3 (Table I), consistent with the absence of clear joint inflammation in the latter one (Table III). As in nonimmune mice, the retention of both mBSA and aBSA in immune mice is also significantly higher after injection of $60 \mu \mathrm{g}$ as compared with $6 \mu \mathrm{g}$, although the differences are less pronounced (Fig. 3 $A b, A c$ and Fig. $3 B b, B c$ ). The latter may be due to differences 

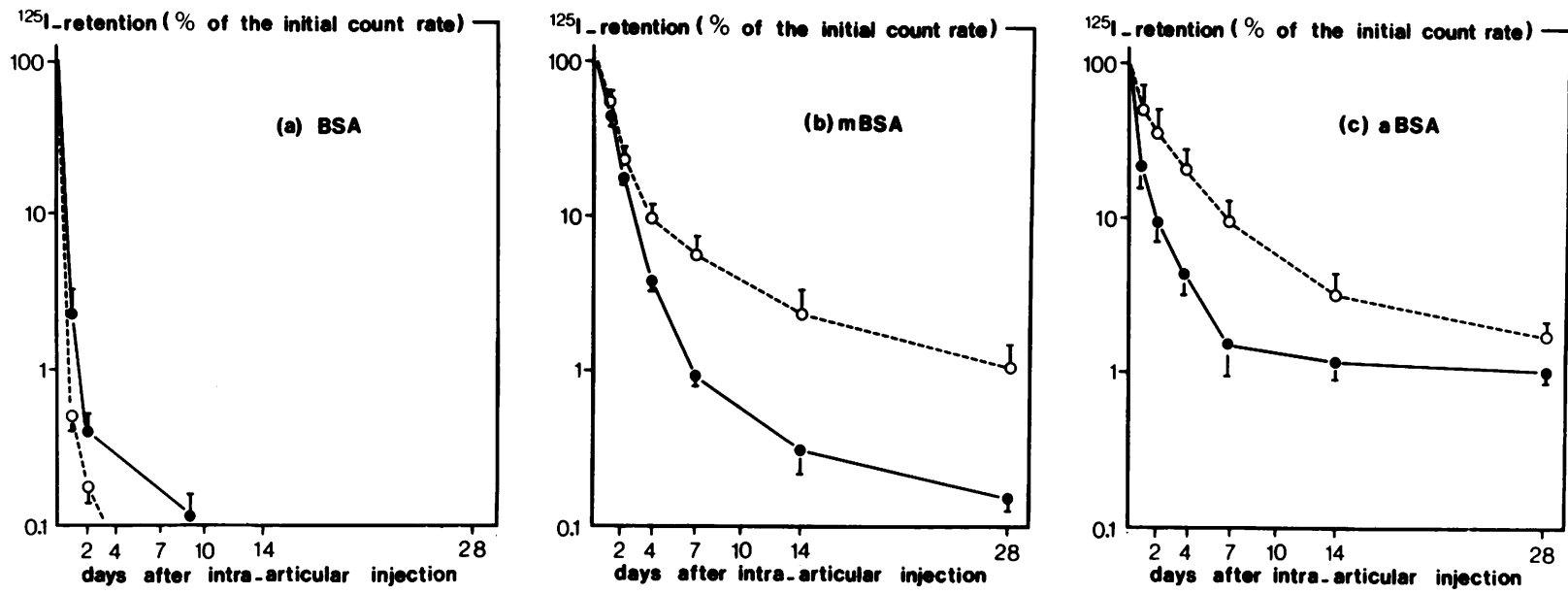

Figure 2. External radioactivity measurements at various days after intraarticular injection of $60 \mu \mathrm{g}{ }^{125} \mathrm{I}$-antigen into the knee joint of nonimmune (--- $-_{---)}$and immune $(-\bullet-)$ mice

(groups 3, 6, and 7; Table I). Values represent the mean \pm SDcalculated from groups of five mice.

in severity of joint inflammation after injection of the various doses. An interesting observation is the horizontal slope of the retention curve of aBSA in the late phase (Fig. $3 B c$ ), indicative for augmentation of antigen retention by antibody-mediated mechanisms.

The difference between the immune and nonimmune groups is the presence of antibodies and the development of joint inflammation in the former one.

To investigate the role of inflammation in antigen clearance and retention, unilateral joint inflammation was induced with different doses of aOA in aOA/FCA immunized mice, and the retention of ${ }^{125} \mathrm{I}-\mathrm{aBSA}$ was followed both in the inflamed and the contralateral noninflamed joint. Table IV shows that significantly more inflammation is induced with the highest dose of aOA. Significantly less aBSA is retained in the inflamed joints as compared with the contralateral joints in both aOA

Table III. R/L Ratio of ${ }^{99 m}$ Tc Uptake at Various Days after Intraarticular Injection of Antigen into the Right Knee Joint

\begin{tabular}{|c|c|c|c|c|c|}
\hline \multirow[b]{3}{*}{ Day } & \multicolumn{5}{|c|}{$\mathrm{R} / \mathrm{L}$ ratio of ${ }^{99 \mathrm{~m}} \mathrm{Tc}$ uptake } \\
\hline & \multirow{2}{*}{$\frac{\mathrm{BSA}}{60 \mu \mathrm{g}^{*}}$} & \multicolumn{2}{|l|}{ mBSA } & \multicolumn{2}{|l|}{ aBSA } \\
\hline & & $60 \mu \mathrm{g}$ & $6 \mu g$ & $60 \mu \mathrm{g}$ & $6 \mu \mathrm{g}$ \\
\hline 2 & $1.07 \pm 0.05 \ddagger$ & $2.03 \pm 0.34$ & $1.68 \pm 0.21$ & $1.85 \pm 0.41$ & $1.56 \pm 0.17$ \\
\hline 7 & $1.02 \pm 0.04$ & $1.72 \pm 0.18$ & $1.37 \pm 0.08$ & $1.57 \pm 0.16$ & $1.21 \pm 0.09$ \\
\hline 14 & ND & $1.33 \pm 0.10$ & $1.15 \pm 0.04$ & $1.22 \pm 0.11$ & $1.12 \pm 0.05$ \\
\hline
\end{tabular}

* Dose of intraarticular antigen.

¥ Mean values \pm SD calculated from groups of at least five mice. Values represent measurements in immunized mice (see Table I: groups 3, 6 and 7). R/L ratios $>1.1$ were not found with any of the antigens injected into nonimmune mice. dose groups, but the effect was most pronounced in the highest aOA dose group (Table IV). In an additional experiment, we investigated the effect of nonimmune zymosan-induced inflammation on the handling of ${ }^{125} \mathrm{I}-\mathrm{aBSA}$. Unilateral joint inflammation was induced with either 180 or $18 \mu \mathrm{g}$ zymosan. On day 7 , the joints injected with 180 and $18 \mu \mathrm{g}$ zymosan contained only 35 or $59 \%$ antigen, respectively, as compared with the contralateral joint.

In conclusion, the overall pattern of antigen retention in FCA-immunized mice is dependent on antagonizing forces: inflammation, which may enhance antigen clearance, and antibodies, which may enhance antigen retention. The relative contribution of these two forces will be highly dependent on the antigen dose.

In vitro studies. To investigate antigen binding at collagenous tissue and articular cartilage of the joint, whole patellae, containing surrounding collagenous tissue and intact patellar cartilage, were dissected and incubated with ${ }^{125}$ I-labeled antigen, with or without preincubation of the tissue with antibodies. Fig. 4 shows the retention of BSA in collagenous tissue after preincubation with normal serum and with different antibody concentrations. Considerable retention was only achieved after preloading of the tissue with high titered, undiluted anti-BSA serum. Fig. 5 a shows the dependence of the amount of antigen retained on the amount of antigen supplied. In the absence of antibody preloading, the retention of native BSA was too low to be depicted in Fig. $5 \mathrm{a}$. In the presence of antibodies, an initial increase of retention of native BSA was found with increasing antigen concentrations, but a plateau, which represents the maximal antibody-mediated antigen binding capacity, is readily reached. For the cationic antigens, a continuous increase of the binding was found with increasing antigen concentrations, and in the dose range studied, this 

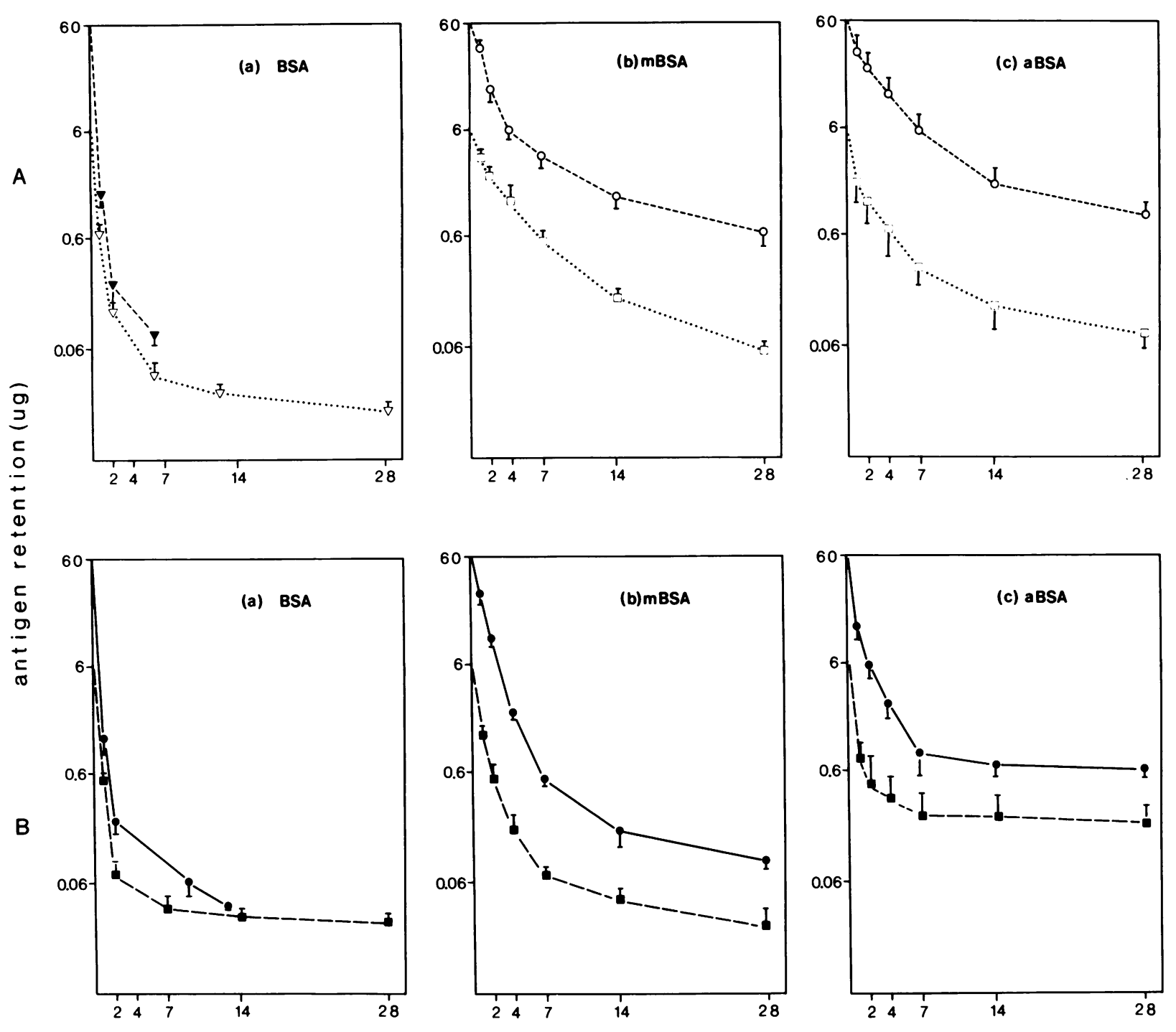

days after intra-articular injection

Figure 3. $(A)$ External radioactivity measurements at various days after intraarticular injection of two doses $(6 \mu \mathrm{g}, \cdots \nabla \cdots ; 60 \mu \mathrm{g}$, - - - - - -) of ${ }^{125}$ I-BSA into the knee joints of immune mice (group 5; Table I) and two doses ( $6 \mu \mathrm{g}, \cdots \square \cdot \cdots ; 60 \mu \mathrm{g},----_{---)}$of cationic antigen into nonimmune mice. Values represent the

nonimmune binding can not be augmented by preloading of the tissue with antibodies. After incubation with an antigen concentration of $10 \mathrm{mg} / \mathrm{ml}$, which is the dose used for the induction of chronic arthritis, 100 times more cationic antigen could be bound as compared with the antibody-mediated trapping of native BSA.

For hyaline articular cartilage, this difference is even greater. The antibody-mediated trapping of native BSA in the dense mean \pm SD of groups of five mice. $(B)$ Injection of two doses $(6 \mu \mathrm{g}$, $-----; 60 \mu \mathrm{g},-\bullet-$ ) in immune mice (groups 3, 6, and 7; Table I). The amount of radioactivity retained of the highest dose of BSA was too low to allow accurate external counting at later days, so these values have been deleted.

structure of the hyaline patellar cartilage was almost absent, whereas considerable nonimmune binding of the cationic antigens was found (Fig. $5 \mathrm{~b}$ ). To obtain evidence that nonimmune binding of the cationic antigens was due to charge interactions, incubations were also performed at $\mathrm{pH} 9.5$ instead of $\mathrm{pH}$ 7.0. Under these conditions, the binding of $\mathrm{mBSA}$ and aBSA to the patellar cartilage was reduced to 28 and $3 \%$, respectively. A similar reduction in antigen binding was ob- 
Table IV. Effect of Concomitant aOA-induced Inflammation in $a O A / F C A$ Immunized Mice on the Retention of ${ }^{125} I-a B S A$

\begin{tabular}{|c|c|c|c|c|}
\hline \multirow[b]{2}{*}{ Day } & \multicolumn{2}{|c|}{ Retention of ${ }^{125} \mathrm{I}$-aBSA* } & \multicolumn{2}{|l|}{ Inflammation§ } \\
\hline & $\begin{array}{l}\mathrm{aOA} \\
(1 \mathrm{mg} / \mathrm{ml})\end{array}$ & $\begin{array}{l}\mathrm{aOA} \\
(0.1 \mathrm{mg} / \mathrm{ml})\end{array}$ & $\begin{array}{l}\mathrm{aOA} \\
(1 \mathrm{mg} / \mathrm{ml})\end{array}$ & $\begin{array}{l}\mathrm{aOA} \\
(0.1 \mathrm{mg} / \mathrm{ml})\end{array}$ \\
\hline 2 & $53 \pm 15 \ddagger$ & $48 \pm 10^{\prime \prime}$ & $2.28 \pm 0.24$ & $1.69 \pm 0.16 \pi$ \\
\hline 4 & $25 \pm 7$ & $43 \pm 13$ & $1.76 \pm 0.20$ & $1.34 \pm 0.22 \pi$ \\
\hline 7 & $17 \pm 5$ & $42 \pm 6 \pi$ & $1.48 \pm 0.18$ & $1.20 \pm 0.11 \pi$ \\
\hline
\end{tabular}

* One knee joint was injected with ${ }^{125} \mathrm{I}$-aBSA alone and the contralateral joint with both $\mathrm{aOA}$ and ${ }^{125} \mathrm{I}-\mathrm{aBSA}$.

$\ddagger$ Percentage of ${ }^{125} \mathrm{I}-\mathrm{aBSA}$ retained in the inflamed as compared with the contralateral noninflamed joint.

$\S$ Ratio of ${ }^{99 \mathrm{~m}} \mathrm{Tc}$ uptake in the inflamed and noninflamed joint.

"Values represent the mean $\pm S D$ calculated from groups of at least five mice.

I Significant difference $(P<0.01$, Wilcoxon test) between the effect of a high $(1 \mathrm{mg} / \mathrm{ml})$ and low $(0.1 \mathrm{mg} / \mathrm{ml})$ dose of aOA.

served when the ionic strength of the incubation buffer was augmented from 0.15 to $0.5 \mathrm{M}$. In addition, trypsin pretreatment, which lowers the proteoglycan content of the tissue, and therefore, its negative fixed charge density, causes a clear decline in the subsequent binding of mBSA and aBSA (Table V). In contrast, the antibody-mediated trapping of native BSA in the hyaline patellar cartilage was just increased by trypsin pretreatment (Table V).

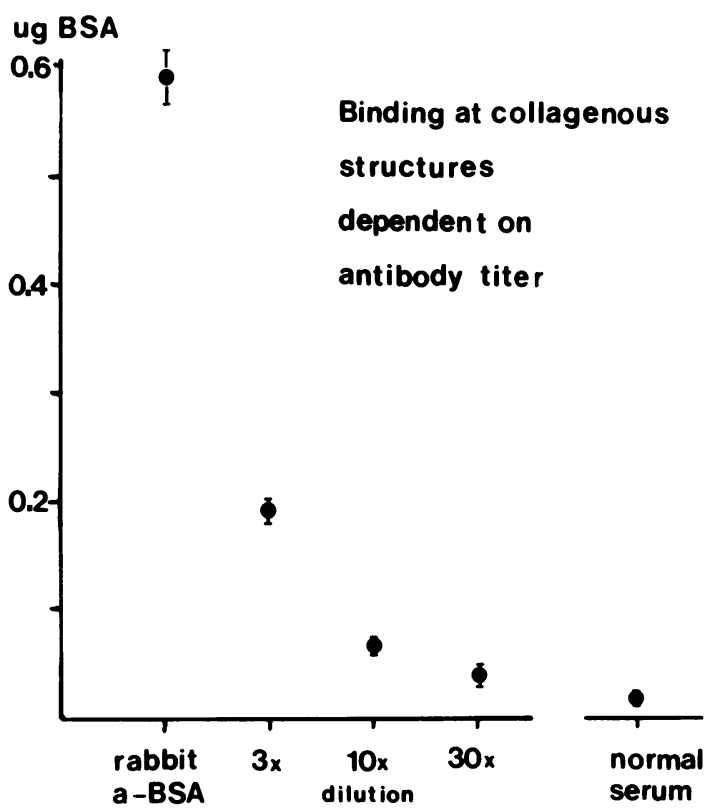

Figure 4. In vitro binding of ${ }^{125} \mathrm{I}-\mathrm{BSA}(0.3 \mathrm{mg} / \mathrm{ml})$ at collagenous tissue of the patella preincubated with normal and anti-BSA antiserum. Values are the mean $\pm S D$ of four tissue specimens and represent micrograms BSA bound per $5 \mathrm{mg}$ tissue (wet weight).

\section{Discussion}

Our data indicate that in the mouse knee joint, chargedependent antigen retention is much greater than that by antibody-mediated trapping. Chronic joint inflammation developed only after intraarticular injection of the cationic antigens mBSA and aBSA, but not BSA, in immunized mice. Since immunization with the three antigens led to comparable humoral and cellular immunity, it seems likely that the development of chronic antigen-induced arthritis in mice is related to the amount of antigen retained in the joint.

Electrical charge, as a factor influencing the glomerular localization of immune complexes, is emerging as an important new concept in renal immunopathology $(9,10)$. The present data show that antigenic charge also plays a definite role in antigen handling by the joint, leading to a considerable increase in the retention of cationic as compared with anionic antigens. Evidence for the electrostatic character of the binding of the cationic BSAs to the articular cartilage emerged from our in vitro observations. Reversing the charge of the antigen by increasing the $\mathrm{pH}$ above their isoelectric point resulted in a clear decline in the binding to the articular cartilage. Similar results were obtained by increasing the ionic strength of the incubation medium. The reverse approach, i.e., leaving the charge of the antigen unaltered, but lowering the negative charge of the cartilage by trypsin pretreatment, which depletes the cartilage of negatively charged proteoglycans, also resulted in diminished binding. The exact nature of the anionic binding sites of the articular cartilage remains to be clarified. A recent electronmicroscopic investigation using cationized ferritin pointed to the thin surface layer of the articular cartilage, which contains proteidic material and fine collagen fibrils, as the anionic binding site rather than the charged proteoglycans in the articular matrix (21).

A potentiating role of antibodies in the retention of cationic antigen was clearly demonstrated in the kidney. In addition to the initial charge-mediated binding, long-term retention is highly dependent on a second phase of antibody deposition, since cationized antigen was cleared largely from the glomerular capillaries within a few hours unless complexed with antibodies (22). Antibodies are apparently not necessary for the initial retention of high amounts of cationic antigen in the knee joint in view of the excellent retention in nonimmune mice (Fig. 3). The shorter time span for persistence of cationic antigen per se in the kidney as compared with the joint may be due to differences in flow or to differences in the anionic binding sites in the two organs. In immunized mice, deposition of antibodies does occur at joint structures containing retained cationic antigen as demonstrated for mBSA by our immunofluorescence studies (3) and for aBSA by the rather horizontal slope of the retention curve (Fig. 3), which is indicative for immune complex retention; yet, an enhancing effect on antigen retention as found in the kidney is less clear. The potential of antibodies to enhance antigen retention is limited by its 


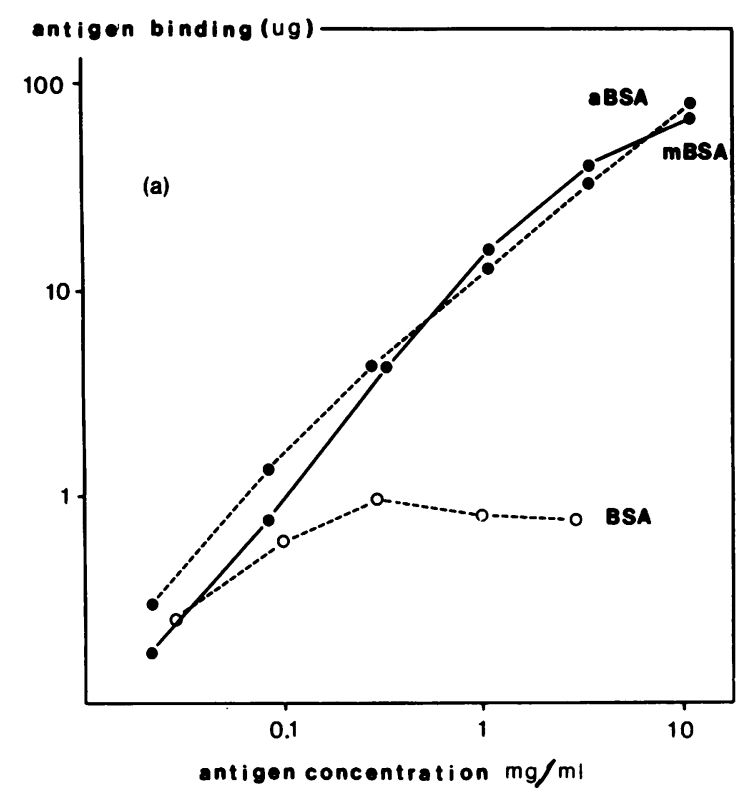

Figure 5. In vitro binding of ${ }^{125} \mathrm{I}-\mathrm{BSA}\left(---0_{---)}\right.$, mBSA $(-\bullet-)$, and aBSA (-- $\bullet---)$ at collagenous tissue $(a)$ and patellar cartilage (b), with (for BSA) or without (for mBSA and aBSA) preincubation with anti-BSA, respectively. Values are the mean of three tissue specimens and represent micrograms antigen bound per $5 \mathrm{mg}$ tissue (wet weight) in (a), and micrograms antigen

concentration and therefore, this mechanism will only be of additional value in the overall antigen retention when low amounts of antigen are used. Another determinant interfering with an enhancing effect of antibodies on antigen retention in immunized mice is the development of joint inflammation in these animals which may increase antigen clearance (20) (Table IV).

Antigen-induced arthritis has been widely studied in the rabbit, and in addition to sufficient antigen retention, the presence of adequate delayed hypersensitivity against the eliciting antigen is likely to be a prerequisite for the development

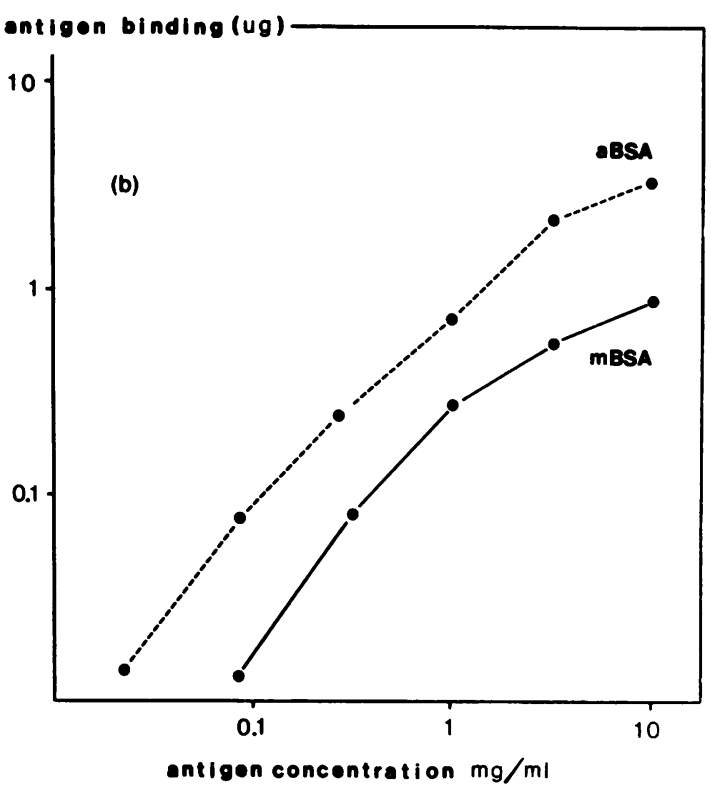

bound per cartilage of the whole patella $(b)$. Values for BSA trapping in patellar cartilage are too low (1-2 ng) to be depicted in $(b)$. The latter represents far less tissue so the figure does not allow quantitative comparison of amounts of antigen bound to collagenous tissue and cartilage.

of chronic arthritis (16). The importance of delayed hypersensitivity in the induction of chronic arthritis with mBSA in mice has recently been demonstrated by Brackertz et al. (12). As far as delayed hypersensitivity against native BSA is concerned, conflicting data have been reported. Crowle et al. (23) claimed that methylation shifts the immune response towards delayed hypersensitivity and that the delayed hypersensitivity to native BSA is much weaker than that to mBSA. Katsura et al. $(15,24)$, however, showed clear development of delayed hypersensitivity to native BSA in mice, and our ear test data are in support of this (Table I). Further evidence for adequate

Table V. Effect of Trypsin Pretreatment on In Vitro Antigen Binding

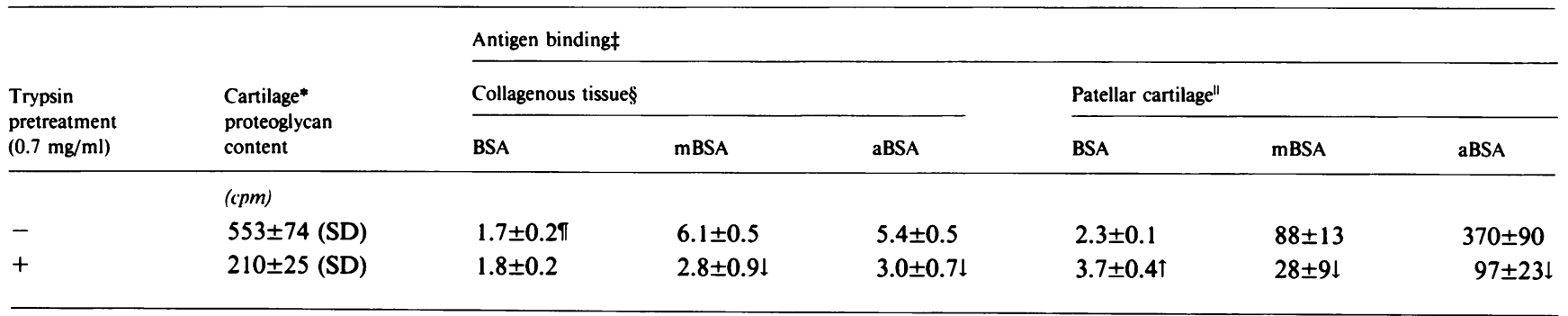

* Cartilage proteoglycan was labeled by incubation in ${ }^{35}$ S-sulphate $(10 \mu \mathrm{Ci} / \mathrm{ml})$. $¥$ Patellae were incubated with ${ }^{125} \mathrm{I}$-antigen $(0.3 \mathrm{mg} / \mathrm{ml})$ with (for BSA) or without preincubation with anti-BSA serum. § Micrograms antigen bound per $5 \mathrm{mg}$ tissue (wet weight). "Nanograms antigen bound at the cartilage of the whole patella. T Values represent the mean \pm SD of two experiments with five tissue specimens each. Arrows indicate significant differences between control and trypsin treatment $(P<0.01$, Wilcoxon test). 
delayed hypersensitivity against native BSA was obtained from our study with repeated intraarticular injections of BSA. Using such a protocol, definite arthritis could be induced in mice immunized with BSA in FCA, but not after immunization with FIA (manuscript in preparation). Since we have no indications for inadequate delayed hypersensitivity, the failure to induce chronic arthritis in mice after a single dose of native BSA seems to be related to insufficient antigen retention. When the retention of native BSA in the mouse knee joint is compared with earlier studies in the rabbit, it is clear that much less antigen is retained, i.e., $<0.1 \mu \mathrm{g}$ in the mouse knee joint against amounts of $10 \mu \mathrm{g}$ in the rabbit knee joint (20), but it remains difficult to interpret these absolute values in animals so different in size. More important, however, than the final retention data probably is the slope of the retention curve in the initial phase after antigen injection. The initial clearance is very fast in the mouse as compared with the rabbit (20). In this respect, the observation of Hasselbacher et al. (25) that appreciable deposition of particulate immune complexes among the collagen bundles of intraarticular tendon and cartilage was delayed until maximal inflammation had occurred within the synovial cavity seems important; due to the fast initial clearance, the bulk of the antigen has already been cleared from the mouse knee joint at the time of maximal antibody-mediated trapping.

In comparing the relevance of antigen binding by chargemediated and antibody-mediated mechanisms for the chronic course of murine joint inflammation, it seems evident that the first mechanism is most important in the induction phase. The amounts of antigen retained by the second mechanism are low and apparently in a range not effective for inflammation induction, but the maintenance of small quantities of immunologically active antigen may play a role in the induction of local hypersensitivity, and therefore, in chronicity of inflammation (26-28). Charge-mediated binding results in retention of large amounts of antigen in a range sufficient for the development of pronounced joint inflammation. In already ongoing arthritis, the relative importance of charge-mediated and antibody-mediated binding may be different. As the inflammation proceeds, joint structures become damaged with concomitant loss of anionic sites. Diminished binding capacity for cationic agents has been demonstrated after trypsin treatment of joint tissues (Table V) and is also supported by the weak binding of mBSA injected for a second time in an already arthritic joint (3). In contrast, in situ immune complex deposition hardly occurs in the dense structure of intact hyaline cartilage in mice, probably due to poor penetration of immunoglobulins, but increased amounts are deposited in cartilage depleted of proteoglycans (Table V). Increased retention has also been demonstrated after repeated intraarticular injection of BSA (20).

The phenomenon of charge-mediated binding of cationic agents to joint structures may have relevance for human chronic arthritis. Fortunately, most naturally occurring proteins are not cationic (29). However, some products of bacteria, e.g., streptococci, are highly cationic and perhaps may find their way to the joint upon release in the circulation. Such agents may either exert a direct toxic effect on the underlying structures or serve as planted antigen for the attachment of antibodies. In addition to antigens, an antibody may show on its own affinity for negatively charged tissues. Antibodies obtained from sera of systemic lupus erythematous patients and believed to be directed against DNA were recently shown to be not that specific, but to cross-react with all kinds of negatively charged polyanions, e.g., hyaluronic acid and glucosaminoglycans (30); such antibodies may perhaps possess affinity for negatively charged structures in the kidneys and the joint, with the potential of inducing localized organ specific pathology. Treatment of glomerulonephritis and arthritis has been approached by immunosuppression and antiinflammatory therapy, but it may be worthwhile to extend the approach to interference with the electrostatic binding of potentially harmful cationic agents. The recent observation that protamine interferes with the binding of exogenous cationic antigen to anionic sites in the glomerular capillary wall and has a beneficial effect on the membranous nephropathy (31) warrants further investigation in this field.

\section{Acknowledgments}

The authors wish to thank Mr. P. B. Spaan and Mr. G. J. F. Grutters and the staff of the Animal Laboratory for technical assistance, and Liduine van den Bersselaar for secretarial assistance.

\section{References}

1. Cooke, T. D., E. R. Hurd, M. Ziff, and H. E. Jasin. 1972. The pathogenesis of chronic inflammation in experimental antigen-induced arthritis. II. Preferential localization of antigen-antibody complexes to collagenous tissues. J. Exp. Med. 135:323-338.

2. Hollister, J. R., and M. Mannik. 1974. Antigen retention in joint tissues in antigen-induced synovitis. Clin. Exp. Immunol. 16:615627.

3. van den Berg, W. B., H. J. van Beusekom, L. B. A. van de Putte, W. A. Zwarts, and M. van der Sluis. 1982. Antigen handling in antigen-induced arthritis in mice. An autoradiographic and immunofluorescence study using whole joint sections. Am. J. Pathol. 108:9-16.

4. Cooke, T. D., E. R. Hurd, H. E. Jasin, J. Bienenstock, and M. Ziff. 1975. Identification of immunoglobulins and complement in rheumatoid articular collagenous tissues. Arthritis Rheum. 18:541-551.

5. Ishikawa, H., J. D. Smiley, and M. Ziff. 1975. Electron microscopic demonstration of immunoglobulin deposition in rheumatoid cartilage. Arthritis Rheum. 18:563-576.

6. Jasin, H. E. 1975. Mechanism of trapping of immune complexes in joint collagenous tissues. Clin. Exp. Immunol. 22:473-485.

7. Teuscher, C., and D. M. Donaldson. 1979. The deposition and formation of immune complexes in collagenous tissues. Clin. Immunol. Immunopathol. 13:56-66.

8. Aston, W. P., T. L. Ward, and T. D. V. Cooke. 1983. The 
specific in vitro antibody-mediated retention of bovine serum albumin by porcine hyaline articular cartilage. Clin. Exp. Immunol. 52:280286.

9. Border, W. A., H. J. Ward, E. S. Kamil, and A. H. Cohen. 1982. Induction of membranous nephropathy in rabbits by administration of an exogenous cationic antigen. Demonstration of a pathogenic role for electrical charge. J. Clin. Invest. 69:451-461.

10. Batsford, S. R., H. Takamiya, and A. Vogt. 1980. A model of in situ immune complex glomerulonephritis in the rat employed cationized ferritin. Clin. Nephrol. (Tokyo). 14:211-216.

11. Gall, E. P., and E. A. Gall. 1980. Histopathogenesis of bovine serum albumin-induced arthritis in the rabbit. J. Rheumatol. 7:13-23.

12. Brackertz, D., G. F. Mitchell, and I. R. Mackay. 1977. Antigeninduced arthritis in mice. I. Induction of arthritis in various strains of mice. Arthritis Rheum. 20:841-850.

13. Danon, D., L. Goldstein, Y. Marikovsky, and E. Skutelsky. 1972. Use of cationized ferritin as a label of negative charges on cell surfaces. J. Ultrastruct. Res. 38:500-510.

14. Hunter, W. M., and F. C. Greenwood. 1962. Preparation of Iodine-131 labelled growth hormone of high specific activity. Nature (Lond.). 194:495-496.

15. Katsura, Y., K. Nakano, Y. Kabara, and I. Uesaka. 1977. Cellmediated and humoral immune responses in mice. I. Necessary conditions for the detection of delayed-type hypersensitivity. Int. Arch. Allergy Appl. Immunol. 53:152-161.

16. Glynn, L. E. 1968. The chronicity of inflammation and its significance in rheumatoid arthritis. Ann. Rheum. Dis. 27:105-121.

17. Kruijsen, M. W. M., W. B. van den Berg, L. B. A. van de Putte, and W. J. M. van den Broek. 1981. 5. Inflammation revisited general topics. Detection and quantification of experimental joint inflammation in mice by measurement of ${ }^{99 \mathrm{~m}} \mathrm{Tc}$-pertechnetate uptake. Agents Actions. 11:640-642.

18. Lens, J. W., W. B. van den Berg, and L. B. A. van de Putte 1984. Quantification of arthritis by ${ }^{99 \mathrm{~m}} \mathrm{Tc}$-uptake measurements in the mouse knee-joint: correlation with histological joint inflammation scores. Agents Actions. 14:723-728.

19. van den Berg, W. B., M. W. M. Kruijsen, and L. B. A. van de Putte. 1982. The mouse patella assay. An easy method of quantitating articular cartilage function in vivo and in vitro. Rheumatol. Int. 1:165169.

20. van Beusekom, H. J., L. B. A. van de Putte, W. B. van den Berg, W. J. M. van den Broek, and W. C. A. M. Buijs. 1981. Antigen handling in antigen-induced joint inflammation: kinetics of a second intra-articularly injected dose of antigen in an already established antigen-induced joint inflammation. Immunology. 44:153-161.

21. Stanescu, R., and S. J. Leibovich. 1982. The negative charge of articular cartilage surfaces. An electron microscopic study using cationized ferritin. J. Bone Jt. Surg. Am. Vol. 64:388-398.

22. Vogt, A., R. Rohrbach, F. Shimizu, H. Takamiya, and S. Batsford. 1982. Interaction of cationized antigen with rat glomerular basement membrane; in situ immune complex formation. Kidney Int. 22:27-35.

23. Crowle, A. J., C. C. Hu, and A. Patrucco. 1968. Preferential development by mice of delayed hypersensitivity to purified basic proteins. J. Allergy. 42:140-156.

24. Katsura, Y. 1977. Cell-mediated and humoral immune responses in mice. III. Dynamic balance between delayed-type hypersensitivity and antibody response. Immunology. 32:227-235.

25. Hasselbacher, P., J. L. Nacht, D. A. Labosky, and M. E. Steinberg. 1980. Antigen-induced arthritis: an immunohistologic study of articular tissue and synovial fluid using the horseradish peroxidase technique. J. Rheumatol. 7:596-607.

26. Tew, J. G., T. E. Mandel, and P. L. Rice. 1980. Immune elimination and immune retention: the relationship between antigen retained in the foot and the elicitation of footpad swelling. Immunology. 40:425-433.

27. van den Berg, W. B., J. W. Lens, L. B. A. van de Putte, and H. J. van Beusekom. 1982. Antigen induced arthritis: antigen handling and chronicity of joint inflammation. Agents Actions Suppl. 11:233241 .

28. Lens, J. W., W. B. van den Berg, and L. B. A. van de Putte. 1984. Flare-up of antigen-induced arthritis in mice after challenge with intravenous antigen: studies on the characteristics of and mechanisms involved in the reaction. Clin. Exp. Immunol. 55:287-294.

29. Malamud, D., and J. W. Drysdale. 1978. Isoelectric points of proteins: a table. Anal. Biochem. 86:620-647.

30. Faaber, P., P. J. A. Capel, G. P. M. Rijke, G. Vierwinden, L. B. A. van de Putte, and R. A. P. Koene. 1984. Cross-reactivity of anti-DNA antibodies with proteoglycans. Clin. Exp. Immunol. 55:502508

31. Adler, S. G., H. Wang, H. J. Ward, A. H. Cohen, and W. A. Border. 1983. Electrical charge. Its role in the pathogenesis and prevention of experimental membranous nephropathy in the rabbit. $J$. Clin. Invest. 71:487-499. 